\title{
EXPERIENCES IN THE DEVELOPMENT OF AN INFORMATION SYSTEMS TO SUPPORT ENTERPRISE SUSTAINABILITY COURSE
}

\author{
Ricardo Chalmeta, Manuel Mollar \\ Grupo de Integración y Re-ingeniería de Sistemas. Dept. Lenguajes y Sistemas \\ Informáticos. Universitat Jaume I (SPAIN)
}

\begin{abstract}
The Universitat Jaume I (UJI) of Castellón, Spain and the National Distance Education University (UNED) are teaching together the Master's Degree in Corporate Sustainability and Social Responsibility. The main objective is to study the concepts of sustainability and corporate social responsibility (CSR) and their multiple dimensions in more depth. The course emphasizes the applicability of existing management and assessment tools, the policies and strategies implemented at all organizational levels involving CSR, and the mechanisms for dialogue and interaction with the main stakeholders and interest groups.
\end{abstract}

This master's degree aims to train professionals to practically apply the approach of ethics, sustainability and social and environmental responsibility to existing business models, and to other public and private organizations, such as not-for profit organizations and government public bodies.

The master is composed of different courses. One of them is the information systems to support enterprise sustainability course. It equips students with the necessary basic knowledge and competencies they need to design and utilise information systems to support enterprise sustainability effectively and efficiently.

The aim of this paper is to describe the course objectives, the target competencies, the course contents, the assessments, and how the teaching methodology and the resources are used to teach the subject.

Keywords: Corporate Sustainability and Social Responsibility, information systems to support enterprise sustainability, learning experiences.

\section{INTRODUCION}

Business sustainability or Corporate Social Responsibility (CSR) and can be defined as "the voluntary integration of social and environmental concerns in the enterprises' daily business operations and in the interaction with their stakeholders. In a broader sense it is defined as a concept whereby companies decide voluntarily to contribute to a better society and a cleaner environment" [1].

To the degree that environmental and social issues are reflected in market transactions and with the growing importance of environmental and social issues many companies have implemented specific environmental or social management systems during the last decade. These systems have, however, rarely been integrated with the general management system of a firm. As a consequence, environmental and social management is often not linked to the economic success of the firm and the economic contribution of environmental and social management therefore remains unclear [2].

Several authors have pointed at opportunities to develop the well-established Business Balanced Scorecard (BSC), proposed by Kaplan and Norton in 1996, into a Scorecard that enables companies to integrate sustainability into their strategy [3]. The BSC provides "a framework that translates strategy into action" which is organised around four perspectives (Financial, Customers, Processes and Training).

Students of the Master's Degree in Corporate Sustainability and Social Responsibility needs to know how to include the dimensions of ecological and social sustainability within corporate strategic considerations and how to manage them using the BSC.

This paper describes the information systems to support enterprise sustainability course of the Master's Degree in Corporate Sustainability and Social Responsibility at the Universitat Jaume I (UJI) of Castellón, Spain and the National Distance Education University (UNED). It shows the target 
competencies, the course contents, the assessments, and how the teaching methodology and the resources are used to teach the subject.

\section{OBJECTIVES}

The objective of the course is to show students a tool that enables them to implement the concepts of sustainability in business organisations day-to-day management, integrating the social and environmental concepts within the management models.

Therefore, the course shows students the process and steps of formulating a Sustainability Balanced Scorecard. A Sustainability Balanced Scorecard is a Balanced Scorecard (BSC) that integrates the three dimensions of sustainability - economic, environmental and social - simultaneously. To do this, the methodologies showed in [4] and [5] are followed.

\section{LEARNING OUTCOMES/CAPABILITY DEVELOPMENT}

\subsection{Specific capabilities}

- To understand how information and information systems relate in the total enterprise for strategic Sustainability decisions

- To build and implement Sustainability balanced scorecard planning and management systems

- To develop Communications strategy and change management of the Sustainability balanced scorecard

- To select appropriate software to collect and report Sustainability information throughout the organization

- To cascade the Sustainability scorecard throughout the organization

\subsection{Cognitive Capabilities}

- Computer literacy

- Analytic/design (conduct research, analyse, reason, solve problems, interpret data)

- Appreciative (evaluate ideas, make judgements, think critically, multidisciplinary perspectives, self-recognition)

\subsection{Behavioural Capabilities}

- Personal (think and act independently, creativity, tolerant of ambiguity, flexible)

- Interpersonal (listening, presentation, communicate, negotiate, group dynamics, collaboration)

\section{LEARNING METHODOLOGY}

Learning methodology uses Active Learning. Active Learning involves students directly and engages them actively in the learning process itself. Students are involved in all stages of planning, design, execution and evaluation.

Active Teaching Methods used in the course are Group projects, Questionnaires, Practical work, Brainstorming, Group discussion, Case studies, Sharing experiences, Group work.

Active Teaching Methods used Out of School are: Surveys, Market research, Questionnaire design

\section{SYLLABUS/COURSE CONTENT}

\subsection{Active Learning}

The main objective of the active learning is that students apply the methodologies showed in [4] and

[5] to an organization. They have to do it in groups composed by 5 students. The methodologies are 
organised in phases and outlines the activities to be performed, the techniques and supporting tools to be used, and the expected results for each phase.

So, the students have to carry out the following activities to develop a Sustainability balanced scorecard in an organization:

\subsubsection{Phase I: Preliminary}

Before beginning the work is fundamental to explicitly carry out certain important features such as Management's formal commitment, the identification and beginning of talks with those who are going to be the main stakeholders, and the viability of the project.

\subsubsection{Phase II: Project Planning}

In this phase the Project plan is created. This involves defining the activities to be carried out, the sequence they are to be carried out in and the resources needed, as well as the quality control mechanisms and planning of the management of change.

\subsubsection{Phase III: Designing the Business Framework}

In this phase, the competitive environment of the organization, with a clear orientation towards the fundamental concepts of CSR, is analysed from both an internal organisational perspective, by reviewing and specifying its mission, vision, values, strategies and policies, and an external perspective, by analysing the competitive environment in which the organisation will have to act in order to compete in current or potential markets. The results of this analysis will make it possible to define the Critical Success Factors (CSF) that will allow its sustainability goals to be reached.

\subsubsection{Phase IV: Designing the Strategic Balanced Scorecard}

In addition to the perspectives that are taken into account in the original BSC (Financial, Customers, Processes, Technology and Training), two new perspectives (Social/Labour and Environmental) have to be implemented so as to be able to apply the requirements of sustainability within the BSC. Then, the objectives and indicators have to be defined by perspective.

In order to define the indicators for measuring the scope of the objectives set out in the Sustainability balanced scorecard properly, the following aspects must be taken into account by the students, according to [6] and [7]:

Single identifier
Description of the aim of the indicator
Perspective it belongs to
Person who guarantees fulfilment
Category (if it is from the 'internal processes'
perspective)
Algorithm or formula for calculation
Data for calculating it and source of those
data

Standard reference value

Maximum value

\begin{abstract}
Minimum value
Scale of measurement

Period of validity - can be unlimited

Time interval in which it is to be calculated

Degree of importance (low, normal, high)

Analysis and interpretation of the result Initiatives for fulfilling the indicator

Actions to be followed if it is out of range
\end{abstract}

\subsubsection{Phase V: Process Design and Improvement}

Once the strategic aims of the enterprise and the indicators for measuring the extent to which they are being fulfilled have been defined, the business processes must be analysed in case it were necessary to redesign them so as to be able to fulfil the sustainability strategic objectives.

Besides including the classical standards of the ISO 9000 series in the processes of continuous change, other standards have to be considered:

- As a reference to the new social and labour perspective, while also seeking a set of standards that allow work conditions to be improved, the recommendations in the OHSAS1 18000 series

\footnotetext{
${ }^{1}$ OHSAS 18000 series, Occupational health and safety management systems - specification.
} 
should be taken as the international standards concerning the management of occupational safety and health.

- With respect to the new environmental perspective, the ISO 14000 standards will be the reference norms serving as an environmental management system to ensure control over and compliance with a large number of legal requirements related to environmental issues.

A map of processes must be developed by the students that describes the current situation (AS-IS model) and shows the deficiencies, opportunities for improvement and changes that must be introduced (TO-BE model).

\subsubsection{Phase VI: Deployment of the Scorecard by business units}

The objectives and indicators defined at the strategic level must be deployed by the students in a set of tactical and operational objectives and indicators. The intention here is to link the proposed indicators by evaluating the strategic decisions with the indicators in order to measure the results at the tactical and operational level throughout the different business units or processes. The models of the processes produced in phase $\mathrm{V}$ make it easier to identify the appropriate indicators for each of them. It thus becomes possible to stimulate all the members of the enterprise to participate in an effort to achieve the fulfilment of the business sustainability strategy.

\subsubsection{Phase VII: Validation of the Sustainability Scorecard}

During this phase all the proposed indicators must be revised by comparing them with other indicators that were already being used. This will make it possible to detect possible shortcomings as well as any indicators that have been proposed but which in fact are not relevant. It is important to stress that there should be an appropriate number of indicators and the initial tendency to define a large number of them should be avoided since many will not eventually be of any use.

The validation of the indicators detected in the new perspectives must take into account both the degree of fulfilment of the criteria defined to select them and their validity as a support in decisionmaking. In order to begin to act on the indicators of the new perspectives, they must be estimated subjectively and it must be possible to quantify these estimations by analysing similar indicators from companies within the sector that stand out for their model of management.

Another point to be taken into account is to check whether the deployment of the indicators from the strategic to the tactical and operational level has been carried out properly.

In this phase of the Sustainability Scorecard project, the students will have to design the information and communications infrastructure that is capable of extracting the data for calculating the indicators, processing them and communicating them. It should be pointed out, as suggested by some authors, that this is one of the main obstacles preventing enterprises from having an adequate Sustainability Scorecard.

\subsubsection{Phase VIII: Implementation of the Sustainability Scorecard}

The people in a company are the key to any business strategy and determine the success or failure of the Sustainability Scorecard. Therefore, the aim of this phase is to ensure that all members of the organisation are familiar with the Sustainability Scorecard project. Training courses for enterprise employees have to be designed by the students.

\subsubsection{Phase IX: Control and Follow-up}

Two different activities are carried out in this phase: exploitation of the Sustainability Scorecard (visualisation of performance and decision) and management of its development.

\section{ASSESSMENT}

Final qualification of the course is calculated from the following qualifications:

- $50 \%$ from the result obtained in a written exam

- $50 \%$ from the Group project 


\section{CONCLUSIONS}

This paper shows the curriculum design of information systems to support enterprise sustainability course. This curriculum has been developed by two teachers of computer systems department at Universitat Jaume I.

Students are very satisfied with course contents and organization. The course is focused in practical work, so theory can be understood easier, and students obtain new knowledge and new skills, similar to professional work.

\section{REFERENCES}

[1] Commission of the European Communities, (2001). Brussels COM (2001) 366.

[2] Figge, K., Hahn, T., Schaltegger, S., Wagner, M., 2002. The sustainability balanced corecard linking sustainability management to business strategy. Business Strategy and the Environment 11, 269-284.

[3] Van der Woerd, F., Van den Brink, F., 2004. Feasibility of a Responsive Business Scorecard _ a pilot study Journal of Business Ethics 55: 173-186.

[4] Kaplan R, Norton D. 1996. The Balanced Scorecard:Translating Strategies into Action. Harvard Business School Press: Boston, MA.

[5] Chalmeta, R. \& Palomero, S. Journal of the Operational Research Society (2011) 62: 1344.

[6] León, R., Muñoz, M.J., Chalmeta, R., 2010 Methodology for Sustainability Strategic Planning and Management. Industrial Management and Data Systems IVol. 110 (2) pp. 249-268.

[7] Chalmeta, R., Palomero, S., Matilla, M., 2011. Methodology to develop a performance measurement system in small and medium-sized enterprises, International Journal of Computer Integrated Manufacturing, 25:8, 716-740.

[8] Lohman, C. Fortuin, L., and Wouters, M., 2004. Designing a performance measurement system: a case study. European Journal of Operational Research, 156(2), 267-286. 